\title{
Awareness Towards Rabies and Exposure Rate and Treatment of Dog-Bite Injuries Among Rural Residents - Guangxi Zhuang Autonomous Region, China, 2021
}

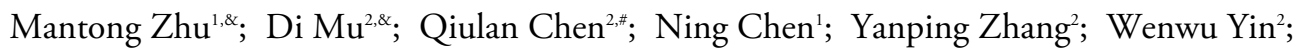 \\ Yu Li²; Yingjie Chen"; Y Yidan Deng'; Xianyan Tang'
}

\section{Summary \\ What is already known about this topic? \\ Although fatal once clinical signs appear, rabies is preventable through three proven, effective interventions including mass dog vaccination, post- exposure prophylaxis (PEP), and, though sometimes neglected, awareness of rabies. \\ What is added by this report? \\ The total awareness rate of rabies-related knowledge among rural residents was only $57.9 \%$ in Guangxi Zhuang Autonomous Region, one of the provincial- level administrative divisions (PLADs) with endemic rabies in China, and the exposure rate of dog-bite injuries was as high as $7.2 \%$ in the past year. In addition, $14.8 \%$ of bite victims failed to seek PEP service. \\ What are the implications for public health practice? \\ This study can provide evidence for the targeted prevention and control program of rabies in rural areas and help realize the international goals of eliminating dog-mediated rabies by 2030 .}

Rabies is almost always fatal once symptoms appear, causing approximately 59,000 deaths worldwide each year (1). However, rabies is preventable through three proven, effective interventions. Except for mass dog vaccination and post-exposure prophylaxis (PEP), awareness of rabies is also important (2-3). In 2015, the World Health Organization (WHO), the World Organisation for Animal Health (OIE), and the Food and Agriculture Organization of the United Nations (FAO) in collaboration with Global Alliance for Rabies Control (GARC) proposed eliminating dog-mediated rabies globally by 2030 ("Zero by 30") (3). China is one of the countries in Asia that is most affected by rabies, with the vast majority of rabies cases occurring in rural areas (4). Among human rabies cases, more than $99 \%$ of cases were caused by bites from rabid dogs
(5). However, in the last five years, there have been few reports on the rabies awareness and the exposure rate of dog-bite injuries, especially in rural areas. In order to fill the gaps, this study conducted a cross-sectional survey on awareness towards rabies and exposure rate and treatment of dog-bite injuries using a uniform structural questionnaire to interview 2,544 rural residents in Guangxi Zhuang Autonomous Region in 2021. The study found that in Guangxi, the total awareness rate of rabies-related knowledge among rural residents was only $57.9 \%$, and the exposure rate of dog-bite injuries was as high as $7.2 \%$ in the past year. However, $14.8 \%$ of those bitten did not seek PEP services. Much more effort should be made for promoting the awareness of rabies disease and the accessibility of PEP service in rural China, especially in the endemic areas. In addition, it is necessary to design targeted prevention and control program for promotion.

A multistage random sampling method was used in this study. To estimate the sample size, the sample was divided into 3 layers according to age and 2 layers according to gender for a total of 6 layers. It was assumed that the awareness rate was $50 \%$, and the test level $\alpha$ was set to 0.05 and the allowable error was set to $5 \%$. According to the simple random sampling sample size calculation formula and considering the loss-follow-up rate of $10 \%$ known in previous studies, the minimum sample size was calculated to be 2,534 people. Overall, 127 villages were randomly selected in Guangxi, and 20 interviewees were selected in each village based on systematic sampling method. Finally, a total of 2,544 people aged from 15 to 75 years old with verbal consent were investigated face to face.

There were 6 basic rabies-related questions for respondents to answer. Points were awarded as follows: 0 for incorrect or unclear answers, 1 for correct answers, and a full score was 6 . If the final total score $\geq 4$, the respondents were classified as having awareness. The test level $\alpha$ was set to 0.05 and used the chi- 
squared test to analyze the awareness rate of different populations. Finally, a value was assigned to the awareness situation ( 0 =unknown, $1=$ awareness $)$, and the influencing factors were analyzed by binary logistic regression. The survey subjects were asked about whether they have been bitten by dogs in the past year, as well as the situation of treatment after being bitten. The exposure rate of dog-bite injuries among rural residents in Guangxi was calculated $=$ (number of bitten/number of people investigated) $\times 100 \%$. Excel (version 2017, Microsoft Corporation, Beijing, China) was used for data collation, and $\mathrm{R}$ (version 4.0.5, University of Auckland, New Zealand) was used for statistical analysis.

The survey subjects were all rural residents, including 1,246 males and 1,298 females, with an average age of $44.6 \pm 17.0$ years old. The survey subjects were mainly young people (15-44 years old), followed by middle-aged people (45-59 years old) and elderly people (60 years old and above), accounting for $45.8 \%$, 31.6\%, and $22.6 \%$, respectively. The education levels of the population were primarily junior high school, followed by primary school and below and high school and above, accounting for $37.5 \%, 37.4 \%$, and $25.1 \%$, respectively. The total awareness rate of rabies-related knowledge was $57.9 \%$. The awareness rate of single questions ranged from $28.8 \%$ to $92.8 \%$. Overall, $9.4 \%$ respondents had never heard of rabies, and $55.7 \%$ of respondents did not know that rabies was incurable (Table 1).

The results of single-factor analysis showed that there were significantly statistical differences in the awareness rate among subjects in different age groups and different education levels $(P<0.05)$, and there was no significantly statistical difference in awareness rate between female and male $(P>0.05)$. For both men and women, the older the age, the lower the awareness rate, among which the group over 60 years old was the lowest, with $42.6 \%$ and $32.9 \%$, respectively. Among subjects with different education levels, the awareness rate of the subjects with education level of primary school or below was the lowest at only $37.2 \%$ (Table 1). The results of multifactor analysis showed that the education level of the respondents was an influencing factor of the awareness rate. Compared to the primary school and below, the respondents with

TABLE 1. The awareness rate of rabies-related knowledge for 2,544 rural residents in Guangxi Zhuang Autonomous Region, 2021.

\begin{tabular}{|c|c|c|c|c|c|c|c|c|c|}
\hline Variable & $\begin{array}{c}\text { Point } 1 \\
\mathrm{n}(\%)\end{array}$ & $\begin{array}{c}\text { Point } 2 \\
\mathrm{n}(\%)\end{array}$ & $\begin{array}{c}\text { Point } 3 \\
\text { n (\%) }\end{array}$ & $\begin{array}{c}\text { Point } 4 \\
\mathrm{n}(\%)\end{array}$ & $\begin{array}{c}\text { Point } 5 \\
\mathrm{n}(\%)\end{array}$ & $\begin{array}{c}\text { Point } 6 \\
\mathrm{n}(\%)\end{array}$ & $\begin{array}{c}\text { Total points } \\
\mathbf{N}(\%) \\
\end{array}$ & $\chi^{2}$ value & $P$ value \\
\hline \multicolumn{10}{|l|}{ Male } \\
\hline 15-44 (years) & $511(95.0)$ & $282(52.4)$ & $439(81.6)$ & $520(96.7)$ & $352(65.4)$ & $213(39.6)$ & $386(71.7)$ & \multirow{4}{*}{74.040} & \multirow{4}{*}{0.000} \\
\hline 45-59 (years) & $386(92.1)$ & $179(42.7)$ & $302(72.1)$ & $384(91.6)$ & $203(48.4)$ & $99(23.6)$ & $223(53.2)$ & & \\
\hline$\geq 60$ (years) & $252(87.2)$ & $117(40.5)$ & $193(66.8)$ & $254(87.9)$ & $90(31.1)$ & $54(18.7)$ & $123(42.6)$ & & \\
\hline Total & $1,149(92.2)$ & $578(46.4)$ & $934(75.0)$ & $1,158(92.9)$ & $645(51.8)$ & $366(29.4)$ & $732(58.7)$ & & \\
\hline \multicolumn{10}{|l|}{ Female } \\
\hline 15-44 (years) & $601(95.9)$ & $300(47.8)$ & $543(86.6)$ & $610(97.3)$ & $422(67.3)$ & $239(38.1)$ & $456(72.7)$ & \multirow{4}{*}{139.336} & \multirow{4}{*}{0.000} \\
\hline 45-59 (years) & $330(85.7)$ & $152(39.5)$ & $267(69.4)$ & $356(92.5)$ & $171(44.4)$ & $88(22.9)$ & $192(49.9)$ & & \\
\hline$\geq 60$ (years) & $225(78.7)$ & $96(33.6)$ & $167(58.4)$ & $237(82.9)$ & $86(30.1)$ & $39(13.6)$ & $94(32.9)$ & & \\
\hline Total & $1,156(89.1)$ & $548(42.2)$ & $977(75.3)$ & $1,203(92.7)$ & $679(52.3)$ & $366(28.2)$ & $742(57.2)$ & & \\
\hline \multicolumn{10}{|l|}{ Level of education } \\
\hline Primary school and below & $800(83.8)$ & $323(33.8)$ & $589(61.7)$ & $831(87.0)$ & $326(32.8)$ & $160(16.1)$ & $370(37.2)$ & \multirow{4}{*}{283.038} & \multirow{4}{*}{0.000} \\
\hline Junior high school & $889(93.4)$ & $433(45.5)$ & $757(79.5)$ & $910(95.6)$ & $520(54.6)$ & $289(30.4)$ & $592(62.2)$ & & \\
\hline High school and above & $616(96.7)$ & $370(58.1)$ & $565(88.7)$ & $620(97.3)$ & $478(75.0)$ & $283(44.4)$ & $512(80.4)$ & & \\
\hline Total & $2,305(90.6)$ & $1,126(44.3)$ & $1,911(75.1)$ & $2,361(92.8)$ & $1,324(52.0)$ & $732(28.8)$ & $1,474(57.9)$ & & \\
\hline $\begin{array}{l}\text { Note: Question 1: Have you } \\
\text { Question 2: Can rabies be c } \\
\text { Question 3: Do you know th } \\
\text { Question 4: What do you thi } \\
\text { Question 5: Do you know th } \\
\text { Question 6: Do you know wh } \\
\mathrm{n} \text { : Number of respondents w } \\
\mathrm{N} \text { : Number of the responden }\end{array}$ & $\begin{array}{l}\text { heard of rabie } \\
\text { ured? } \\
\text { at rabies can } \\
\text { ink should be } \\
\text { at dogs shoul } \\
\text { here to vaccin } \\
\text { vho answered }\end{array}$ & $\begin{array}{l}\text { es (rabies)? } \\
\text { be prevented } \\
\text { done after be } \\
\text { d also be vac } \\
\text { late dogs aga } \\
\text { correctly; n\% } \\
\text { ded as aware }\end{array}$ & $\begin{array}{l}\text { by injection } \\
\text { eing scratchec } \\
\text { ccinated agair } \\
\text { ainst rabies? } \\
t=(\mathrm{n} / \mathrm{number}\end{array}$ & $\begin{array}{l}\text { (vaccine)? } \\
\text { d or bitten by } \\
\text { nst rabies? }\end{array}$ & a dog (cat)? & & & & \\
\hline
\end{tabular}


junior high school [odds ratio $(\mathrm{OR})=2.04,95 \%$ confidence interval $(\mathrm{CI}): 1.67-2.50, P<0.05]$ and high school and above $(\mathrm{OR}=4.29,95 \% \mathrm{CI}$ : 3.27-5.66, $P<0.05)$ had higher awareness rate.

The exposure rate of dog-bite injuries among the respondents was as high as $7.2 \%(183 / 2,544)$ in the past year. Among these 183 victims, 162 reported the situation of their PEP. Overall, 85.2\% (138/162) of dog-bite injuries victims sought PEP services, of which $40.0 \%$ were treated in township hospitals, $23.7 \%$ in county CDCs, $23.0 \%$ in county hospitals, and $13.3 \%$ in village clinics (Table 2). In addition, 7.3\% (10/138) among PEP seekers had not received the vaccine against rabies; $14.8 \%(24 / 162)$ of the victims failed to seek PEP service after dog bites. As for the reasons, $75.0 \%$ respondents answered as "no need to go to hospital", 29.2\% selected "expensive cost", 29.2\% chose "long distance", and $29.2 \%$ thought there was no time to go to doctor (Table 3).

\section{DISCUSSIONS}

The survey showed that the awareness rate of rabies among rural residents in Guangxi was lower than 60\%, especially the group aged above 60 years old and those with low education level. The exposure rate of dog-bite injuries in rural areas of Guangxi was relatively high, and over half of the victims preferred to seek PEP

TABLE 2. The medical institutions of $135^{\star}$ dog-bite injuries victims seeking PEP services in Guangxi Zhuang Autonomous Region, 2020.

\begin{tabular}{lcc}
\hline \multicolumn{1}{c}{ Medical institution } & Respondents & Proportion (n/N) \\
\hline Village health room / clinic & 18 & $13.3 \%(18 / 135)$ \\
Township hospital & 54 & $40.0 \%(54 / 135)$ \\
County hospital & 31 & $23.0 \%(31 / 135)$ \\
County CDC & 32 & $23.7 \%(32 / 135)$ \\
Total & 135 & $100.0 \%(135 / 135)$ \\
\hline
\end{tabular}

Abbreviation: PEP=post-exposure prophylaxis.

* Three victims did not answer this question.

TABLE 3. The reasons of 24 dog-bite injuries victims for not going to the hospital for treatment in Guangxi Zhuang Autonomous Region, 2020.

\begin{tabular}{lcc}
\hline \multicolumn{1}{c}{ Reason } & Respondents & Proportion $(\mathbf{n} / \mathbf{N})$ \\
\hline No need to go to hospital & 18 & $75.0 \%(18 / 24)$ \\
Expensive cost & 7 & $29.2 \%(7 / 24)$ \\
Long distance & 7 & $29.2 \%(7 / 24)$ \\
No time & 7 & $29.2 \%(7 / 24)$ \\
Else & 3 & $12.5 \%(3 / 24)$ \\
\hline
\end{tabular}

service in township hospitals or the village clinics. Unfortunately, nearly one-fifth of victims failed to seek PEP service with the main reason of being ignorant of the rabies threat. In addition, a small number of PEP seekers did not receive a rabies vaccine.

In this study, we found that the rabies awareness rate of rural residents in Guangxi in 2021 was similar to that in Guangxi in 2010 (G), as well as that in rural areas of Rongcheng City, Shandong Province in 2021 (7), but lower than the survey results in rural areas of Pingliang City, Gansu PLADs in recent years (8). This indicated that health education for rabies in rural areas needs to be further strengthened. Low education levels were the hindering factor of the rabies awareness rate; however more than one-third of respondents had an education level lower than primary school. To further popularize knowledge about rabies, targeted material and methods should be developed to ensure local rural residents especially the elderly and low education level population could easily accept.

The exposure rate of dog-bite injuries among rural residents in Guangxi was significantly higher than that of $2.18 \%$ in Hunan Province (9), even though both were rabies-endemic areas. The disparity may be attributed to differences in dog raising rates and dog densities between the two areas. After dog bites, timely and standardized PEP service is the key to preventing rabies (10). But nearly one-fifth of dog bites victims failed to seek PEP service and still a small number of PEP seekers did not receive a rabies vaccine. By the scaling up of the rabies vaccination demonstration zone project during the period of 2009-2016, the number of rabies cases in Guangxi has dropped significantly from 324 to 41 (11), and continue to decrease to only 11 in 2020, which may have led to a relaxation of people's vigilance against rabies. However, this survey showed the high exposure rate of dog-bite injuries in rural residents of Guangxi, which indicated that the risk of rabies remains high, as well as the necessity of constraining dogs to prevent dog-bite injury in rural areas.

We also found that most of the victims preferred to seek PEP service in township hospital and the village clinics, which may be due to convenience and shorter distances when compared with county hospitals. This suggests the necessity to improve the standardization and accessibility of PEP in rural areas especially in rabies endemic regions. First, professionals in township health centers and village clinics should be trained to have the knowledge and skills for PEP treatment after being bitten or scratched by a risk animal. Second, 
township health centers and village clinics, even in remote areas, should be equipped with wound treatment facilities, the rabies vaccine, and rabies immunoglobulin if appropriate. These can improve the accessibility and correct implementation of PEP by the above measures, which can help to achieve the goal of eliminating rabies as soon as possible (12).

This study was subject to some limitations. First, only a preliminary investigation was conducted on where rural residents chose to go for medical treatment after being bitten by dogs, without further investigation into detailed reasons. Second, when investigating the exposure rate of dog-bite injuries, the number of exposures was not questioned in detail. This may lead to a low exposure rate, but when compared with the results in other regions, the exposure rate of dog-bite injuries in this study was still significantly higher, which has important significance.

Conflicts of interest: No conflicts of interest.

Acknowledgement: Animals Asia and all the college student volunteers.

doi: $10.46234 / \mathrm{ccdcw} 2021.260$

\# Corresponding author: Qiulan Chen, chenql@chinacdc.cn.

\footnotetext{
School of Public Health, Guangxi Medical University, Nanning, Guangxi Zhuang Autonomous Region, China; ${ }^{2}$ Division of Infectious Disease, Key Laboratory of Surveillance and Early Warning on Infectious Disease, Chinese Center for Disease Control and Prevention, Beijing, China; ${ }^{3}$ Animals Asia, Chengdu, Sichuan, China.

${ }^{\&}$ Joint first authors.
}

Submitted: September 13, 2021; Accepted: November 13, 2021

\section{REFERENCES}

1. Hampson K, Coudeville L, Lembo T, Sambo M, Kieffer A, Attlan M, et al. Estimating the global burden of endemic canine rabies. PLoS Negl Trop Dis 2015;9(4):e0003709. http://dx.doi.org/10.1371/journal.pntd. 0003709.

2. Ruan S. Modeling the transmission dynamics and control of rabies in China. Math Biosci 2017;286:65 - 93. http://dx.doi.org/10.1016/j. mbs.2017.02.005.

3. World Health Organization. Zero by 30: the global strategic plan to end human deaths from dog-mediated rabies by 2030 . https://www.who.int/publications/i/item/9789241513838. [2021-8-5].

4. Mu D, Tao ZF, Li ZJ, Li Y, Tao XY, Zhu WY, et al. Analysis of epidemic characteristics of human rabies in China in 2007-2018. Chin J Exp Clin Virol 2021;35(2):168 - 71. http://dx.doi.org/10.3760/cma. j.cn112866-20201013-00261. (In Chinese).

5. Zhou HP, Liu YJ, Zhang XJ, Zhu L, Huang BX. Global epidemic situation and elimination strategies of rabies. Chin Anim Health Inspect 2015;32(1):50 - 2. http://dx.doi.org/10.3969/j.issn.1005-944X.2015. 01.019. (In Chinese).

6. Mo Y, Mo ZJ, Liu B, Tan Y, Mo JJ, Li H, et al. A cross-sectional study on kownledge, attitude and practice regarding Rabies on rural residents in Guangxi. J Appl Prev Med 2010;16(6):343 - 5. http://dx.doi.org/10. 3969/j.issn.1673-758X.2010.06.010. (In Chinese).

7. Chen LF, Qiao DL, Jiang B, Xiao ZG, Guo YK, Kong QY, et al. Investigation on KAP of rabies prevention and treatment knowledge in Rongcheng, Shandong. Anim Breed Feed 2021;20(3):126 - 9. http:// dx.doi.org/10.3969/j.issn.1671-427X.2021.03.057. (In Chinese).

8. Ren RF, Ren RQ, Lin ZY, Li L, Liu L. Investigation and analysis on the cognition degree of rabies among rural residents in Kongtong District of Pingliang City, Gansu Province. J Med Pest Control 2019;35(5):488 90,493. http://dx.doi.org/10.7629/yxdwfz201905024. (In Chinese).

9. Yang H, Li BX, Luo KW, Sun QL, Zhang HJ, Zhao SL, et al. Investigation on rabies exposure and its influencing factors in population in rural areas of Hunan Province. J Trop Dis Parasitol 2021;19(1):19 - 24. http://dx.doi.org/10.3969/j.issn.1672-2302.2021. 01.005. (In Chinese).

10. Zhou H, Li Y, Chen RF, Tao XY, Yu PC, Cao SC, et al. Technical guideline for human rabies prevention and control (2016). Chin J Epidemiol 2016;37(2):139 - 63. http://dx.doi.org/10.3760/cma.j.issn. 0254-6450.2016.02.001. (In Chinese).

11. Wei XK, Xiong Y, Li XN, Zheng M, Pan Y, He XX, et al. Vaccination demonstration zone successfully controls rabies in Guangxi Province, China. BMC Infect Dis 2018;18(1):386. http://dx.doi.org/10.1186/ s12879-018-3301-8.

12. Chen QL, Ma XY, Rainey JJ, Li Y, Mu D, Tao XY, et al. Findings from the initial Stepwise Approach to Rabies Elimination (SARE) assessment in China, 2019. PLoS Negl Trop Dis 2021;15(3):e0009274. http://dx. doi.org/10.1371/journal.pntd.0009274. 